\title{
Proceedings of the Society of British Neurological Surgeons: 75th meeting
}

\begin{abstract}
The 75th Meeting of the Society of British Neurological Surgeons was held in Harris College, Preston, on 19 and 20 May 1967. The President, Mr. Wylie McKissock (London), was in the Chair. During the course of the meeting the fourth Sir Hugh Cairns Memorial Lecture, entitled 'Beyond the diagnosis', was delivered by Professor Almeida Lima (Lisbon).
\end{abstract}

\section{THE TREATMENT OF INTRACRANIAL ANEURYSMS}

KENNETH TUTTON (Preston) discussed the rationale of operative treatment for intracranial aneurysms. He said that the problem would be simplified if we could estimate the natural history of an aneurysm in each individual case. He felt that small aneurysms in an early stage often gave symptoms indicative of their presence and, if left untreated, remained a threat to life from further haemorrhage or pressure on vital structures. He felt that in the acute problem natural mortality was probably less than surgical but in long-term results surgical treatment had better results to offer than nature. Unless the patient was conscious and reasonably alert, surgery in the acute stage was harmful but if operation was delayed until the patient had recovered from the acute effects of bleeding, real cure was possible in a high proportion of cases. The presence of spasm in larger arteries and their branches might well be a determining factor.

He felt that a good case could be made out for operating on posterior communicating type aneurysms in the early stage but middle cerebral aneurysms could be safely left until recovery from the initial episode was advanced. With anterior communicating aneurysms they always waited until the patient was fully conscious and, if possible, orientated. In some cases, further haemorrhages might determine early operation but in such circumstances mortality and morbidity was greatly increased. In some cases the onset of arterial spasm, demonstrated by angiography, might be an indication for operation.

ALEX DAwS (Preston) then described the surgical technique employed in these cases. He said that their policy was to use controlled respiration, moderate hypothermia $\left(30^{\circ} \mathrm{C}\right.$.), and intravenous urea or Mannitol. Under such conditions they had been able to use temporary clips on feeding and emptying vessels which allowed an unhurried and detailed technique with careful dissection of the aneurysm sac. They had rarely had to resect any brain for access or use forceful retraction.

With middle cerebral aneurysms the carotid was exposed first and clipped, then the Sylvian fissure opened and the sac displayed. A temporary proximal clip on the middle cerebral allowed adequate examination and clipping of the sac or its neck. With carotid aneurysms their aim was to place a clip on the aneurysm neck and temporary adjustable clamps on the common carotid in the neck were often used. The approach was from above, or, if the aneurysm lay completely behind the carotid, under the temporal lobe. With anterior communicating aneurysms their aim was to obtain a cure by intracranial clipping and total ablation of the lesion. They used an interhemispheral approach with division of the falx and sagittal sinus anteriorly. Temporary control of both internal carotid arteries and usually both proximal and distal anterior cerebral artery, sometimes bilaterally, was extensively used.

In 79 cases of middle cerebral aneurysm, 10 had died and 44 made an excellent recovery; in 66 anterior communicating aneurysms, 14 had died and 36 made good recoveries; in 118 of carotid aneurysms, 20 had died and 89 made good recoveries.

THE SURGICAL REMOVAL OF CIRSOID ANEURYSMS FROM FUNCTIONALLY IMPORTANT AREAS OF THE BRAIN

J. C. CHRISTENSEN (Buenos Aires) described his experiences in a series of 18 cases of cirsoid aneurysm in functionally important areas of the brain. He described his surgical technique in detail and stressed the importance of using moderate hypothermia to $30^{\circ} \mathrm{C}$. by external body cooling, hyperventilation, and systemic hypotension to $80-90 \mathrm{~mm}$. Hg. He aimed at total excision of the lesion by careful dissection. Sometimes ligation of feeding vessels at some distance to the angioma was helpful, though vessels should, where possible, be ligated as close to the lesion as possible. He noted that previous bleeding often made operation easier as the haemorrhage seemed partially to dissect out the angioma from the brain. A complete preoperative angiographic study was essential to identify all the feeding and draining vessels.

Using this technique he had removed angiomas from the Sylvian fissure, the sensorimotor area and even the first and second temporal convolutions of the dominant hemisphere.

Five of six patients without preoperative haemorrhage had shown excellent results without any increase of neurological deficit. The sixth died after several operations. The results were less good in 11 patients with acute preoperative bleeding. Three patients operated on in coma did not survive though one lived for three months. The remaining nine were good results though 